\title{
HispanismeS
}

Revue de la Société des Hispanistes Français

$18 \mid 2021$

Murs, barrières, obstacles dans les mondes

hispaniques II

\section{Ethos del confinamiento: espacio y personajes en En la orilla de Rafael Chirbes (2013)}

Ethos du confinement : espace et personnages dans En la orilla de Rafael

Chirbes (2013)

Ethos of confinement: space and characters in En la orilla by Rafael Chirbes

(2013)

Jimena Larroque

\section{OpenEdition}

Journals

\section{Edición electrónica}

URL: https://journals.openedition.org/hispanismes/14832

DOI: 10.4000/hispanismes.14832

ISSN: 2270-0765

Editor

Société des Hispanistes Français

\section{Referencia electrónica}

Jimena Larroque, «Ethos del confinamiento: espacio y personajes en En la orilla de Rafael Chirbes

(2013)», HispanismeS [En línea], 18 | 2021, Publicado el 31 diciembre 2021, consultado el 30 enero

2022. URL: http://journals.openedition.org/hispanismes/14832 ; DOI: https://doi.org/10.4000/

hispanismes. 14832

Este documento fue generado automáticamente el 30 enero 2022.

\section{(c) $($ †) $\ominus$}

Les contenus de cette revue sont mis à disposition selon les termes de la Licence Creative Commons Attribution - Pas d'Utilisation Commerciale - Pas de Modification 4.0 International. 


\title{
Ethos del confinamiento: espacio y personajes en En la orilla de Rafael Chirbes (2013)
}

\author{
Ethos du confinement : espace et personnages dans En la orilla de Rafael \\ Chirbes (2013) \\ Ethos of confinement: space and characters in En la orilla by Rafael Chirbes \\ (2013)
}

Jimena Larroque

«Por decirlo claramente, si lo de dentro de los libros no tuviera que ver con lo de fuera, o apenas tuviera que ver con lo de fuera, la literatura me parecería un soberbio aburrimiento» ${ }^{1}$. Esta aseveración de Rafael Chirbes contiene toda una declaración de intenciones sobre el pulso realista que lo anima y la intención de enmarcar los personajes de sus ficciones en un espacio y devenir históricos. Pues bien, en un estudio monográfico sobre En la orilla (ELO en adelante) considerábamos que el espacio podía leerse bajo el prisma de las implicaciones políticas de su narrativa² ${ }^{2}$ Así apuntábamos a la necesaria consideración política tanto del tiempo -a cargo de múltiples personajesnarradores cuyas memorias están en conflicto-, como de un espacio relevante desde el título mismo de la novela. En otra reciente publicación, aunque escrita con anterioridad, ya habíamos descrito un cronotopos saturado de malditismo que se desprendía de su lectura ${ }^{3}$. Volver al lugar del crimen, a orillas de ese pantano polisémico, nos permite estimar el modo en que dicho espacio determina el ethos de los personajes, en particular el de Esteban, protagonista de la novela. Por lo tanto, nos preguntamos hasta qué punto puede desprenderse de la caracterización de los personajes en un espacio dado una práctica novelística que se inscribe en la prolongación del naturalismo y que en la reactualización chirbesiana pudiera sentar las bases del realismo del siglo entrante.

2 Conviene primero identificar esta novela como exponente de la «novela espacial» que María del Carmen Bobes Naves teorizaba, en 1984, respecto al ejemplo de Vetusta en La 
Regenta de Clarín, para colmar una carencia que hasta entonces existía, al menos en la crítica española, respecto al espacio como dimensión teórica crucial en los estudios de narrativa:

El espacio no ha sido, entre los elementos de la novela, el que se ha estudiado con mayor interés ya que la teoría literaria no dispone de una denominación para sus unidades de abstracción paralelas a las que se tiene para las acciones en las funciones, o para los personajes en los actantes. Pero teniendo en cuenta que dicho espacio puede ser analizado como un elemento de construcción o distribución de la materia literaria y que puede ser interpretado como un signo literario ambiguo y polivalente, enfoca su estudio desde varias perspectivas en su forma y significación: espacio físico, espacio social y espacio psicológico4.

3 Más recientemente, la crítica anglosajona reafirma la necesidad de la centralidad del espacio en los estudios literarios ${ }^{5}$, como ya lo había hecho la metáfora espacial en las ciencias sociales y humanas, heredera de los estudios postcoloniales y denominada spatial turn en los años 1980 y 1990. Fue entonces cuando se consolidó la referencia al espacio, base común a una transversalidad en los fenómenos sociales, políticos y humanísticos, y que cuajó entre importantes teóricos franceses (G. Deleuze, M. Foucault, P. Bourdieu, M. de Certeau) como terreno de cultivo de cierto «lugar de saber» ${ }^{6}$. Prueba de la confluencia entre ciencias sociales y literarias, serían las palabras del geógrafo Bernard Debarbieux:

Parce qu'il exprime un besoin collectif de positionnement entre passé, présent et futur, le territoire est façonné par la mémoire collective. Il est tout autant le cadre spatial dans lequel s'inscrivent les pratiques et les représentations spatiales d'une société que le produit de ces représentations, l'enveloppe symbolique dans laquelle se dessinent les destins individuels et collectifs ${ }^{7}$.

Retomando la idea de la centralidad del espacio como «signo literario ambiguo y polivalente» según Bobes Naves, es oportuno también aludir a la heterotopía de Foucault cuya atención se sitúa en los márgenes ${ }^{8}$. Pasemos pues a enumerar los elementos que componen una heterotopía de la crisis en sus características espaciales.

\section{Topografía ficticia para la crónica de una crisis}

5 Al igual que otros muchos escritores - por citar solamente algunos en lengua castellana, Alas Clarín, Gabriel Miró, García Márquez, Juan Rulfo, Juan Carlos Onetti, Juan Benet, o Luis Mateo Díez-, Chirbes emprende la creación de lugares imaginarios y ello de manera recurrente en sus novelas de tal modo que va tejiendo una intratextualidad espacial en su narrativa. Es Misent una localidad imaginaria de marcado parecido con Denia y situada en la Marina Alta, comarca al norte de la provincia de Alicante:

[Misent] Ya aparecía en el fondo de La buena letra. Luego en las últimas novelas ha adquirido un primer plano. Inventarte una ciudad te permite cambiar las cosas a tu gusto porque si escoges un paisaje real debes ceñirte a que ahí hay una palmera o allí un banco. Yo soy muy despistado, así que me viene bien

Más allá de la razón práctica y modesta que exime al escritor de compromisos dictados por la geografía real, tenemos en Chirbes la configuración ficticia de un mediterráneo levantino que alterna en ocasiones con ciudades españolas reales. Efectivamente, se menciona Misent por primera vez en La buena letra (1992) ${ }^{10}$ y aparecerá también «la casa de Misent» en Los disparos del cazador (1994) asociado al lugar de retiro donde Carlos Císcar pretendía disfrutar de un lugar confortable como recompensa a una próspera carrera, gracias a turbios negocios como constructor durante la posguerra en 
Madrid. Los otros lugares de la novela son Valencia y Madrid, cuyo tránsito refleja precisamente el recorrido ascensional de este heredero del Torquemada galdosiano, según el propio Chirbes, y del que hará otras versiones, como José Ricart en La caída de Madrid o Matías Bertomeu en Crematorio ${ }^{11}$. Es también Madrid escenario principal de otras novelas donde los personajes encarnan los arquetipos de una nueva clase social emergente en la capital y en esa naciente democracia como ocurre en En la lucha final (1991), La larga marcha (1996) y La caída de Madrid (2000). Los viejos amigos (2003) ofrece por su parte una dialéctica entre la capital, desabrida e inhóspita, y «el adosado en Denia» contrapunto paradisiaco y periférico de otro constructor también llamado Carlos.

7 En el díptico que conforman Crematorio (2007) y ELO (2013), Chirbes crea dos espacios irreales, Misent y Olba, con el objeto de reflejar, más que la crisis económica de 2008 en sí misma, el estado de ánimo de principios de siglo $\mathrm{XXI}^{12}$. El centro neurálgico de Crematorio es Misent, centro urbano en primera línea de playa que había encarnado la época añorada del ladrillo y la explosión de la burbuja inmobiliaria, espacio emblemático de la codicia de los favorecidos por la «cultura del pelotazo»" ${ }^{13}$; mientras que Olba y su pantano, distantes a una veintena de kilómetros de Misent, son los principales escenarios de ELO y representan «la parte de atrás de donde estaba esa agitación $»^{14}$. Se perfila Olba por primera y única vez, como un pequeño pueblo del interior cercano al parque del Montdor, toponimia igualmente inventada, que corresponde probablemente al Parque Natural del Montgó, próximo a Denia ${ }^{15}$. Son pues Misent y Olba las caras de la misma crisis, escaparate y trastienda. Leemos esta descripción en imperfecto de indicativo en la primera parte, titulada «El hallazgo» fechada el 26 de diciembre de 2010 y a cargo de un narrador heterodiegético que dispone minuciosamente el decorado:

Hace tres años, había infinidad de obras en este tramo de La Marina. A ambos lados de la carretera, se sucedían los montones de escombros y las edificaciones en distintas fases constructivas: solares sobre los que empezaba a concentrarse maquinaria; otros en los que la retroexcavadora abría el suelo, sacando de dentro un barro rojizo, o en los que las hormigoneras rellenaban los cimientos. Pilares de los que surgían varas de hierro, tirantes y planchas de mallazo, palés de ladrillos, montones de arena, sacos de morcem. Por todas partes se movían las cuadrillas de albañiles. Algunas fincas en las que las obras habían concluido estaban cubiertas de andamios donde hormigueaban los pintores, mientras en sus aledaños grupos de hombres removían la tierra, ajardinaban, plantaban árboles -viejos olivos, palmeras, pinos, algarrobos- $\mathrm{y}$ arbustos de esos que las guías definen como característicos de la flora ornamental mediterránea: baladres, jazmines, galanes de noche, claveles, rosales, y matas de hierbas aromáticas: tomillo, orégano, romero, salvia. La red de carreteras que cruza la zona soportaba un incesante tráfico de camiones que transportaban palmeras, olivos centenarios que apenas se acomodaban al hueco de las enormes macetas en que los trasladaban, o frondosos algarrobos. El aire se llenaba con el ruido metálico de los vehículos que acarreaban material de obra, contenedores para escombros, autocargantes, góndolas que trasladaban retroexcavadoras, hormigoneras. El conjunto transmitía sensación de activa colmena ${ }^{16}$. (p. 13)

Después de la fiebre constructora, un lacónico «Es la crisis» (p.14) nos sitúa en el presente de la diegésis:

Hace cinco o seis años, todo el mundo trabajaba. La comarca entera en obras. Parecía que no iba a quedarse ni un centímetro de terreno sin hormigonar; en la actualidad, el paisaje tiene algo de campo de batalla abandonado, o de territorio sujeto a un armisticio: tierras cubiertas de hierba, naranjales convertidos en 
solares; frutales descuidados, muchos de ellos secos; tapias que encierran pedazos de nada. (p. 15)

El paso de Misent a Olba (de Crematorio a ELO) se hace con el progresivo desplazamiento del paisaje urbano hacia el paisaje natural. Así pues, la prolongación diegética entre estas dos novelas es explícita: la trama de Crematorio termina con una «Estampa invernal de Misent» (en cursiva y mediante un narrador heterodiegético en el cierre de la novela) y pone el énfasis en el paisaje del litoral:

Mar adentro vuelve a formarse la mancha espesa, como de brea, que ocupa todo el horizonte, mientras que el perfil de la costa está marcado por el reflejo anaranjado de las luces. Se ha detenido otra vez el viento, y a través de esa calma, desde el lugar en el que escarba el perro, se abre paso un olor dulzón, de vieja carroña, que impregna el aire ${ }^{17}$.

10 Esta atmósfera amenazante se prolonga en ELO, con el descubrimiento de unos cuerpos calcinados en su íncipit, enunciado por un narrador igualmente heterodiegético: «El primero en ver la carroña es Ahmed Ouallahi» (p.11), personaje secundario antiguo empleado de la carpintería de Esteban que se encuentra en el marjal. Este nuevo espacio natural, acuático como el precedente, contiene diferentes estratos de tiempo, encajando perfectamente con la función del cronotopo ${ }^{18}$. Nos dice Chirbes en una entrevista de 2014: «De repente me di cuenta de que el pantano tenía una estratigrafía que se correspondía con los estratos de la historia también» ${ }^{19}$. Como J. F. Carcelén afirma que «más que espacio o escenario, el marjal es protagonista, por su dimensión metafórica y simbólica $»^{20}$. El pantano reúne una polisemia de significados que son «emblema de la descomposición del espíritu» $»^{21}$. Chirbes fuerza la metáfora al decir en otra entrevista: «España es un pantano que todo lo va pudriendo» ${ }^{22}$ y en la misma línea, el crítico Fernando Valls presentaba la novela como reveladora de podredumbre ${ }^{23}$. Parece que esta función de revelación es compartida por el autor y el narrador principal, Esteban, ya que desde su experiencia consigue establecer un nexo entre la historia y ese espacio natural: «el pantano ha sido una especie de abandonado patio trasero de las poblaciones cercanas en el que se ha permitido todo y donde se han acumulado basuras y suciedades durante decenios», por mucho que los medios de comunicación lo declaren «el gran pulmón verde de la comarca» (p.41). Y continúa diciendo: «El mar lo lava todo, lo expulsa, o lo fagocita, lo purifica con sus yodos y salitres, lo aprovecha y recicla: se supone que es saludable, no como el pantano [...]. El mar limpia, oxigena, el pantano pudre» (p. 42). Sin embargo, acto seguido, el discurso de Esteban se contradice -el mar ya no limpia sino que acoge a los especuladores y ociosos del mundo- de tal modo que invierte su razonamiento, infundiendo poco a poco cierta sospecha hacia los discursos dominantes que justo antes parecía suscribir:

La orilla del mar no ha sido un lugar hospitalario [...]. En Misent, sin ir más lejos, hay urbanizaciones junto a la playa que se llaman La Laguna, Las Balsas, Saladar o El Marjal [...]. Pero a quién se le ocurre comprarse un bungalow en un sitio que se llama así. Los nombres de los lugares guardan la memoria de lo que fueron. Barrizales. Charcas. Fangales. Balsas para la explotación de sal. Mi padre ha sentido un especial desprecio por la gente que compra chalets y apartamentos en esos terrenos ganados al pantano. En realidad, ha despreciado a cuantos han llegado a la comarca atraídos por la llamada del mar. Golfos. Aventureros. Especuladores. La costa es un sitio pernicioso, decía. El mar trae o atrae la basura, aquí se instala lo peor. Desde siempre: charlatanes, trileros, matones. (p. 43)

11 Se diría que Esteban comparte en adelante la opinión de su padre trasladada en el discurso indirecto, su discurso se construye progresivamente. Aunque el marjal es 
podredumbre, también forma parte de la geografía sentimental de Esteban, donde su tío Ramón le enseñó a pescar y donde aprende el sentido de la muerte:

Del mismo modo que el médico le receta a cada enfermo su medicina, el tío Ramón le ofrecía a cada presa su señuelo y me enseñaba a pensar como un pez, como una anguila, como un pato azulón, mientras aprendía los señuelos de la vida. Te pudrirás, chiquitín. Y apestarás. Como todo el mundo. Mira qué belleza, el color, el dibujo de las plumas en el cuello del pato. Pero está muerto. (p. 52)

Va a ser el pantano el lugar idóneo para escenificar la muerte de Esteban y de su padre, leitmotiv persistente en la novela, y que da título a una amplia segunda parte, la «localización de exteriores»:

No busco sexo. Localizo exteriores. Persigo escenario. O, mejor dicho, voy a reencontrarme con el escenario que tengo elegido de antemano, practico una inspección ocular, como -en los telediarios- dicen que hacen los policías en los lugares en los que se ha cometido un delito: vuelvo al primer lugar del que guardo recuerdo, el que mi tío me mostró y mi padre parece haber añorado siempre. (p. 38)

13 Este párrafo alude en la primera frase al marjal como lugar de promiscuidad sexual, que califica el protagonista como un prostíbulo a cielo abierto «sucio y culpable» (p. 41): «Cuando lo he hecho aquí, en el pantano, perseguía una sensación de libertad, y, sin embargo, me he parecido que no era yo solo quien se manchaba [...], sino que me parecía que se manchaba el propio lugar» (ibid.). El pantano, espacio mancillado, es a la vez espacio de epifanía. Lugar de origen y de muerte del protagonista, el pantano encierra la polisemia de la podredumbre y la vida, la pervivencia y el cambio, y simultáneamente conforma un «cronotopo del no-tiempo»"

[...] el pantano me parece el núcleo de pervivencia de un mundo sin tiempo, que se sostiene a la vez frágil y energético, en el centro del tapiz menguante -verde piel de zapa- que forman los campos de naranjos y pomelos, las plantaciones de frutales, las huertas que beben del pantano gracias a un complicado sistema de acequias. Llamamos naturaleza a formas de artificio que precedieron a las nuestras, no nos paramos a distinguir que los paisajes no son eternos, han estado, y están -como nosotros- condenados a dejar de ser, no siempre más despacio que nosotros mismos. (p. 101)

Aplicando la distinción de Bobes Naves entre espacios -físico, social y psicológico-, Jessica Cáliz identifica la articulación simbólica del espacio novelesco en tres niveles geográficos -la comarca alicantina, las localidades (ficticias) y el espacio natural (el marjal)- como «el microcosmos de la historia reciente de España»" 25 . A orillas de este pantano sin horizonte, de agua estancada, que remite a las virtudes amnésicas del río Leteo, el protagonista trata de revelar lo que no se puede ver, lo que queda relegado en sus márgenes. Espacio paradójico, «indefinido» y polisémico, contribuye al confinamiento y acaba por engullir a Esteban y a su progenitor.

La sensación que produce el confuso paisaje en el que se alternan las superficies acuáticas con las de los lodos y tierra más o menos firme -a veces se trata de barros movedizos-, es la de un mundo inconcluso (lo es: la naturaleza prosigue lenta el proceso de colmatación, el barro forma parte de la laguna al tiempo que la engulle: es, a la vez, nacimiento y agonía), tramposa foto fija del instante en que Dios empezó a separar las aguas de la tierra, geografía sin definir, que sigue haciéndose, detenida en la mañana del tercer día de la creación, si hacerse fuera algo distinto que destruirse: el mismo mecanismo que hizo nacer el pantano le procura su desaparición. Lo que lo engendra lo condena a borrarse. En cualquier caso, espacio indefinido, mundo a medio hacer [...]. (p. 422) 


\section{Ethos del confinamiento y autodestrucción de los personajes}

15 Según el DRAE, el lema ethos (del gr. ท̃ $\theta$ os êthos 'costumbre', 'carácter') designa el «conjunto de rasgos y modos de comportamiento que conforman el carácter o la identidad de una persona o una comunidad». Procedente del arte de la retórica, esta noción desarrollada por Aristóteles ya incluía ambas dimensiones, individual y colectiva, y se refería a la imagen que el orador construye de sí mismo en y por su discurso. En la tradición de la escuela francesa del análisis del discurso, se considera el texto como una producción discursiva dentro de un campo social, «trace d'un discours où la parole est mise en scène» ${ }^{26}$. En este sentido, el ethos recubre la construcción de una escenografía apropiada que busca la identificación y la adhesión del lector; se puede analizar, por lo tanto, mediante la enunciación, la forma de la narración y la puesta en escena del enunciador ${ }^{27}$.

Siendo el de Esteban el punto de vista central de esta novela, en torno al cual se articulan las demás voces narrativas, centramos nuestra atención en el ethos del protagonista, narrador autodiegético atrapado dentro de una "telaraña de voces» (p. 215 y 216). Por orden de aparición y reconocibles por cambios tipográficos exclusivamente, las nueve voces narrativas de ELO se suceden como sigue: narrador heterodiegético, Esteban, Julio (exempleado de la carpintería), Esteban, mujer de Álvaro (igualmente exempleado), Esteban, mujer de Joaquín, Esteban, Joaquín, narrador heterodiegético y padre de Esteban, Esteban, Liliana (exempleada doméstica), Esteban, Tomás Pedrós (el especulador fugitivo) ${ }^{28}$.

17 La caracterización de personajes queda indisolublemente relacionada con el espacio. En Olba viven confinados los personajes de $E L O$, en particular Esteban y su padre, que van a ser las víctimas mortales de la novela por decisión del hijo; otras víctimas lo son también, desde el punto de vista económico y social, los antiguos empleados de Esteban a quienes ha tenido que despedir. Olba, como antes el pantano, es un espacio cerrado que contribuye al confinamiento: «No me bastaba con abrir la ventana para expulsar la angustia, los muros estaban en torno a Olba» (p. 306). Lugar alejado del mundo, pues, de no ser por el esfuerzo discursivo de Esteban: «[...] en los pueblos pequeños se convive gracias a que se echan periódicas capas de olvido sobre las cosas que van pasando [...]» (p. 178). Leemos en esta descripción los imponentes límites del espacio de Esteban:

En cuanto cerraba el taller por dentro, subía la escalera que conduce hasta la casa y me metía en la habitación, para encontrarme en un sitio que no fuera ningún sitio, al principio sentía claustrofobia allí encerrado [...] casi podía verlos allá al fondo, al sur, los límites: el caserío de Misent, los acantilados hundidos en la calima, borrosos, las figuritas de los barcos de pesca que volvían al atardecer seguidos por una bandada de gaviotas; $y$, del otro lado, las estribaciones pedregosas del Montdor. Desde la azotea veía que esos límites se extendían también al norte, el gran vacío del marjal, los carrizales que se pierden de vista; y el perfil de las playas que se ha ido ocultando con el paso del tiempo tras la línea creciente de las urbanizaciones [...]. (p. 306)

La estrechez física del taller corresponde a la falta de ambición profesional de Esteban, que hereda el negocio de su padre y que se ve abocado a «aceptar un futuro cuyos límites coincidían con el taller y la sombra tutelar de mi padre» (p. 169). Precisamente, es el del padre un confinamiento en sentido propio: aunque padece mutismo por un tumor de tráquea extirpado, «No muestra el menor interés en comunicarse» (p. 30). Les 
aleja una distinta aproximación a la propia biografía y a la memoria: el progenitor, hoy nonagenario, tiene un pasado de resistencia durante la Guerra Civil (se escondió en el marjal como fugitivo), y ejerció su oficio de carpintero sacrificando sus anhelos artísticos por su familia. Un narrador heterodiegético permite dar a conocer al lector unas anotaciones, que nunca llegará a leer el hijo, en el reverso de un viejo calendario de este padre mudo. Descubrimos en ellas el relato de heroísmo y dignidad de un "vencido», mientras que para Esteban no son más que valores vanos. Esta discordia existencial entre padre e hijo, nunca expresada mediante el diálogo, llega a conocimiento del lector-receptor, lo que incrementa su pathos (sensibilidad del receptor) respecto al logos (mensaje) del emisor (asociado a un ethos) ${ }^{29}$.

Además del destino común de padre e hijo -la muerte en el marjal que Esteban impone a ambos-, les acerca además un par de definiciones pesimistas sobre «la vida, derroche» (p. 30, 389), el hombre, «un malcosido saco de porquería» (p. 160). Las escenas con el padre son reiteradas, dando una sensación de tiempo detenido, en las que el hijo cuida de aquel en una cotidianeidad lúgubre. Así comienza la segunda parte «Localización de exteriores»: «He sentado a mi padre frente al televisor, de cara a la película del Oeste que ponen cada mañana en la digital terrestre» (p. 29). Estas escenas suelen ser intercambiables: «Enseguida lo volveré a colocar en la butaca (esta vez sin necesidad de atarlo con la sábana, estoy yo para vigilar), y otro ratito de televisión [...]» (p. 154). La casa no es sinónimo de «inmensidad íntima» ${ }^{30}$, muy al contrario, ya que no existe esa intimidad: «ni siquiera masturbarme tranquilamente he podido, siempre la mirada vigilante de mi madre [...]. La voz severa de mi padre [...]» (p. 304). El espacio del taller de carpintería es un lugar de martirio - «he llevado la cruz de la empresa durante más de cuarenta años» (p.304-305)-, lo que contribuye a intensificar la alienación de Esteban respecto a su padre.

Años ochenta, noventa, fin del siglo XX, siglo XXI, siempre solo, rehuyendo los testigos [...]; el taller, la comida con mis padres, luego las comidas sin mi madre, los dos solos, mi padre y yo sin hablarnos, moviéndonos entre las máquinas, entre los tableros, pasándonos las herramientas: un gesto, una orden, coge esto, esto hay que acabarlo antes de cerrar [...], yo como residuo de lo que fue una familia [...], ipor qué al acecho, tabique con tabique, escuchando mis suspiros, los crujidos de la cama, convirtiéndolos en culpa? (p. 192-193)

Dentro de esta esfera doméstica, interviene un tercer personaje, aunque siempre tamizado por el filtro de Esteban: es Liliana, empleada doméstica de origen colombiano, quien representa el exotismo, la dulzura, el afecto incluso. Conocemos por consiguiente la personalidad de Liliana a través del flujo de conciencia de Esteban: «Se muele el maíz, se ponen los frisoles con una hoja de laurel, se calienta el hogo, se pilan los plátanos, se ralla la yuca. La voz de Liliana. Ya verá usted qué rico plato» (p. 35-36). Sin embargo, en el presente diegético, pronto sabemos que Esteban y su anciano padre viven solos: «La voz de ella, cada noche, mientras lo acomodo ante la mesa camilla a la que le he puesto el mantel de hule y en la que le pondré el plato con la verdura, el platito con la tortilla francesa, como hasta hace unos días se los colocaba ella» (p. 30-32). La presencia de Liliana es pues una ilusión percibida exclusivamente en el imaginario del protagonista, muy a menudo asociado a los placeres de la comida y a unos espacios exóticos. Por momentos, como en el siguiente ejemplo, la puntuación desaparece:

Antes se quedaba Liliana contigo, padre, Liliana, la que yo creía que iba a guardarme, la que era tan mía como yo lo soy tuyo. A mí me tendrá siempre, señor Esteban, Liliana, el sancocho el pipián la palma de cera el runrún de su parla, se quedaba con él la mayoría de las veces hasta la hora de la cena, el olor del café el 
olor de las bayas de cacao el olor de los fondosos árboles las hojas frescas recién mojadas por la lluvia del trópico puro verdor y humedad el aire suave de las alturas el estallido de colo de un flamboyán, ¿nunca vio un flamboyán? Es todo flor, una llamarada de fuego escarlata que brota entre el verde de la selva; un poco más allá, el fuego azul del jacarandá, y le daba de comer, y lo bañaba, y ése era el momento que aprovechaba yo para salir a jugar la partida en el bar. (p. 219-220)

Al descubrir el parlamento de Liliana sobre la experiencia vivida en esa casa, insertado relativamente tarde en la narración, entendemos que el personaje de Esteban será incapaz de tomar conciencia de su propia fabulación solipsista:

[...] vaya con el viejo cariñoso, qué se creía, que iba a estar limpiándole el culo al otro y dándole charla a él sin cobrar, eso creía, pero aún tuve ánimos para decirle: y dé usted gracias que no le cuente a mi marido que me quería toquetear y besar. [...] que paguen su avaricia. (p. 400-401)

Cierto es que Esteban se debate entre el afecto sincero y paternal hacia Liliana, y la tentación de la carne para este personaje masculino que vincula irremediablemente el sexo con el dinero («El hombre, bípedo comprador de coños», p. 39). Nótese de nuevo la idea lacerante de la culpa, así como la importancia que tiene el vacío físico, espacial si se quiere, dejado por este personaje femenino en el entorno doméstico del protagonista:

Liliana entre mis brazos, tus labios besándome justo al lado de la barbilla, un par de besos humedecidos con lágrimas, y el contacto con tu cuerpo que se ha pegado al mío buscando protección, mientras yo siento una ternura infinita, una piedad corpórea, porque empiezo a notar que la sangre se concentra, me turbo, no sé cómo moverme, cómo separarme de su cuerpo, porque temo que ella pueda darse cuenta de ese movimiento involuntario de la carne que volvería sucio lo que es verdadera piedad, eres mi niña, Liliana, a la que quiero proteger, no quiero verte sufrir porque me haces sufrir a mí, digo, pero cuerpo y alma parecen desajustados, o resulta que la piedad no es más que una forma enfermiza del deseo. El abrazo, la plenitud de aquellos días, hoy es el hueco, el vacío, una sensación parecida a la que debe de sentir una mujer tras el parto, vaciado por dentro, cuerpo hueco, campana. Sensación de vacío, Liliana, la carpintería, y tú, este silencio, pero también sensación de descanso [...]. (p. 303)

Efectivamente, los desplazamientos de Esteban son mínimos, de la casa familiar, que también incluye el taller de carpintería, creando así un espacio angosto cuyas funciones, familiar y profesional, comunican, al bar Castañer, irónicamente tildado de refugio:

[...] excitante viaje cotidiano, el que por las tardes me saca del aislamiento de la carpintería: calle de San Ramón, donde vivo; del Carmen, de la Paz, paseo de la Constitución (antes General Mola) y ya estoy -como tantas tardes durante tantos años- en el bar Castañer, el refugio [...] permanecen otros componentes de la gasa olfativa que me acuna: el olor de aceites refritos, de lana húmeda, de camiseta de tirantes y de mono de trabajo sudados, olor de cerveza revenida y vino agrio. Ésos aún me permiten identificarlo, recostarme en mi nido y barajar las cartas. (p. 60)

La inminencia de la muerte, leitmotiv de la novela, puntúa la verbosidad de Esteban, desordena el flujo de conciencia en estilo indirecto libre, forma discursiva para expresar la asfixia y la desesperanza:

Olba, hasta el último aliento [...]. Diré adiós antes de que ellos nombren el mal (porque detectarlo ya lo han detectado, un mal transmisible, que hay que mantener a raya) y, en cualquier momento, puedan colgarme del cuello la campanilla de leproso [...]. Que les den. Por fin me siento capaz de decir adiós: aceite quemado café cerveza cazalla vino y lana húmeda. (p. 60) 
Lejos de ser un espacio de encuentro, es el bar de Olba escenario de apariencias, mentiras, ataques, engaños. En él se encuentran otros personajes masculinos, «ellos» en el fragmento que antecede, como el cínico Justino, «ocasional socio de Pedrós» (p. 54) y llamado «nuestro Hannibal Lecter local» o «el depredador» (p.64); Bernal, «el fabricante de telas asfálticas» (p. 41) o también Francisco, amigo de infancia y juventud de Esteban, hijo de vencedores que conoce el éxito en la gastronomía de lujo en Madrid. Todos estos personajes han sabido aprovechar la ocasión de detentar cierto estatus y escapan al confinamiento gozando así de los privilegios del espacio abierto:

Un dandy lejano y fascinante. Su presencia tiraba por elevación en el mundo en cuyos sótanos me había movido con él unos años antes, cuando viajamos juntos, los viajes que, para mí, iban a ser prólogo de algo y fueron epílogo de todo, atrapado en la telaraña de una tejedora de sueños -más bien deseos- llamada Leonor. No para él. Para él fueron la oca sobre la que emprendió el vuelo por encima del mundo [...]. Venía a Olba y cada viaje yo tenía la impresión de que crecía ante mí [...]. Lo que tú digas, Francisco, tú eres el que vienes de fuera, [...], ni siquiera es excitante el cielo estrellado y el olor de azahar, esas cosas que tú dices que tanto echas de menos cuanto estás fuera (p. 176-177).

Esos amigos han traicionado unos ideales de juventud que es el precio a pagar por el éxito en esa España de expansión económica. Para colmo, Francisco sedujo a Leonor, antigua novia de Esteban, con quien vivirá hasta su muerte por un cáncer. Esteban sueña al menos con poder salir de Olba, pero los tratos con Tomás Pedrós le llevan al embargo de la carpintería y a la ruina. Su error, no es el de ser un especulador voraz, sino el de haber querido «levantar una casita para retirarme con el perro Tom» en el Montdor (p. 146). Deberá resignarse a un destino mediocre que acaba en una encerrona definitiva.

También yo quise marcharme, pero cuando vine a darme cuenta, ya no tenía fuerzas para salir de esta casa que me recoge, y no es mía, nunca ha sido mía, es la casa de mis padres con la que avalé -los otros avales fueron la huerta y el terreno de Montdor- una parte del crédito que solicité y cuyo importe uní al dinero que retiré de la cuenta bancaria para poder convertirme en socio paritario en la última promoción de viviendas de Pedrós. No he tenido una casa mía y, de repente, fui socio de varias decenas de viviendas. (p. 303-304)

Por su parte, Tomás Pedrós es el arquetipo del especulador oportunista, cuyo parlamento se encuentra en la tercera parte titulada «Éxodo» que irónicamente se emplea para contar su huida furtiva junto a su mujer, unidos ambos por su pasión por el dinero, mientras que el conjunto de los protagonistas de ELO vive en la inmovilidad física, y en cierto modo histórica: se ha detenido el espacio y el tiempo para ellos de tal modo que el «insilio» (exilio interior) que vivieron los opositores de las izquierdas al régimen franquista ${ }^{31}$, y que experimentó el padre de Esteban, se extiende a la generación siguiente.

Chirbes somete al personaje principal a espacios de opresión -Olba, la casa, carpintería embargada, el bar- de manera que la dialéctica exterior/interior se difumina en favor del campo semántico del encierro con el efecto de la incomunicación entre personajes. Es significativo el empleo anecdótico del discurso directo, en una narración que se sustenta principalmente sobre los monólogos interiores reflejo de una subjetividad exacerbada ${ }^{32}$. La destrucción del mundo idílico en su dimensión espacial ${ }^{33}$ ) engloba la del protagonista, que antes de expirar, ha tomado la palabra en estilo indirecto libre. dónde estoy, no tengo claro si me paro a saludar o si registro en el contenedor» (p. 246). 
No solo el espacio se ve afectado por esta pérdida de contornos que antes hemos indicado, el ethos de los personajes queda reducido a una naturaleza espectral ${ }^{34}$. De esta manera, vemos que el encierro llevado a su paroxismo estimula el surgimiento de un discurso que, si bien se salda por una comunicación frustrada y lleva además aparejada la implosión de los personajes -la de Esteban y su padre, «dos derrotados» (p. 305)-, ofrece sin embargo una ampliación, como un ensanchamiento del espacio. La logorrea de Esteban se salda por un ejercicio de liberación de la palabra y por la muerte.

\section{Notas para el realismo del siglo XXI}

El espacio y la (de-)construcción de personajes que hemos tratado en los puntos anteriores, nos invitan a reflexionar sobre la cuestión del género o redefinición de la novela realista del siglo XXI. Como D. Maingueneau señalaba recientemente, para abarcar el ethos es imprescindible tener en cuenta la configuración histórica del texto, su género y su posicionamiento estético ${ }^{35}$. Para este último punto de nuestra reflexión, consultamos con aprovechamiento los textos de Chirbes en los que, desde el ensayo, formula lo que podríamos denominar una «teoría de la novela», aquella que él pretendía practicar, porque él mismo reconocía con cierta guasa y entre paréntesis (como haciendo una observación de tono menor):

Es verdad que no hay que creerse demasiado al pie de la letra las afirmaciones acerca de la intención literaria que pueda tener un escritor (estamos hartos de leer declaraciones de autores cuyos textos teóricos se dan de bofetadas con lo que ellos dicen que hacen en sus novelas), pero tampoco podemos cerrar tozudamente los ojos, sobre todo en casos como los que acabo de citar, en los que lo que decían pretender y el resultado que expresa su obra se acuerdan con notable precisión. Hay un poderoso hilo de la novela moderna y contemporánea que ha tenido claro que contemplaba la actividad literaria como un arte que, aunque nace en privado, y con frecuencia en la más absoluta soledad [...], sin embargo tiene voluntad pública ${ }^{36}$.

31 Aquellos casos que acababa de citar eran Cervantes, Galdós, Balzac, Flaubert, que tendrían pues la particularidad de ensamblar la individualidad de los personajes con lo público, con la historia: «todos estos grandes novelistas» pretendían «intervenir en algo que ocurría fuera del libro» ${ }^{37}$. Así, esta perspectiva enlaza con el realismo de tipo galdosiano para quien, según Marta Simó, «la exploración existencial es tan importante como la representación de las circunstancias sociales en las que viven inmersos sus personajes y que, inevitablemente, determinan en mayor o menor medida el curso de sus vidas» ${ }^{38}$. Interesa subrayar la idea evolutiva del género realista, y por ello la conveniencia de hablar de «realismos» o formas (en plural) de realismo:

Resulta imposible hablar del concepto de realismo en términos absolutos, pues en cada una de sus manifestaciones intervienen variables de distinta índole: las circunstancias históricas, sociales o políticas que conforman la realidad de ese momento, los fundamentos filosóficos e ideológicos que subyacen en el discurso o el sesgo individualizado que se imprime a cada obra. Todos esos condicionantes hacen que una forma de realismo jamás pueda ser idéntica a otra.

Ni siquiera en una misma época, ni en la trayectoria de un autor, se mantienen incólumes las ideologías y los marcos teóricos ${ }^{39}$. (Anagrama, 2021), Chirbes consigue dar forma a un realismo complejo, coincidente en 
gran medida con la denominada «novela estructural $»^{40}$. Admira en particular los relatos de Juan Eduardo Zúñiga recogidos en Largo noviembre de Madrid (1980) ya que reúne:

[...] la viabilidad de un realismo complejo en el que lo de dentro -la psicología- y lo de fuera -la historia- forman un todo poliédrico, que permite el tejido de una madeja literaria acorde con las exigencias más radicales de la nueva crítica: densidad y saturación de la expresión formal, polisemia (referencias múltiples y complejas), reelaboración canónica de la tradición, ejemplificación de la narración y capacidad para convertirse en símbolo, etc. ${ }^{41}$

Lo mencionábamos al tratar de la invención topográfica de Misent y Olba, la misma estrategia narrativa sirve para construir Crematorio que ELO, puesto que se amplifica la fuerza alegórica de estas ficciones. Dice pues de la primera:

Estilicé el espacio, la geografía, detuve el tiempo, vacié el texto de cualquier trama que no fuera la propia tensión del lenguaje. No quería hacer una novela policíaca, ni contar que hay corrupción y ladrillos por todas partes. Quería contar el estado del alma humana, la mía, la nuestra, en un mundo asít ${ }^{42}$.

En otro lugar, ya afirmamos la conveniencia de considerar la perspectiva transnacional de ELO, basándonos en los trabajos de S. Clingman, que no se ciñe solamente a una problemática peninsular, y ello tanto desde el punto de vista temático como formal ${ }^{43}$. Tenemos por una parte una serie de temáticas de naturaleza transnacional presentes en las novelas de Chirbes: desequilibrios económicos y medioambientales, corrupción, poder del dinero que gobierna las relaciones afectivas, familiares y sexuales, el declive del cuerpo en un contexto de obsesión higienista en torno a la salud, etc. Da importancia «[al] sexo y el dinero [ya que] son los espacios en los que la palabra vuelve a recuperar su función denotativa» y remata diciendo que, después de La Celestina, «habrá que esperar cuatrocientos años para que Balzac o Galdós construyan también personajes en los que el alma es un accidente de la economía, una forma de vestir» ${ }^{44}$.

Pero también la cuestión de la forma en Chirbes es decisiva para poder «contar el estado del alma humana» a principios del siglo XXI, que es lo mismo que poder alcanzar el sentido alegórico y universal deseado:

[...] busco que la literatura sea una búsqueda por entender los mecanismos del mundo que me rodea y mi lugar en él. La literatura como búsqueda y el concepto de belleza ligado al de conocimiento, es bello lo que me hace ver las cosas -las que sean- desde un lugar nuevo y más rico. Saber que el estilo, siendo lo único (un libro es escritura), es fruto de ese esfuerzo y, como diría el evangelio, se nos dará por añadidura. Carmen Martín Gaite decía que la urgencia trae la forma ${ }^{45}$.

La «poética» resultante parte de un presupuesto según el cual no hay fórmulas predefinidas que pudieran encajar en un supuesto género realista, la obra se va haciendo a medida que el texto se construye, del mismo modo que el discurso de Esteban y su ethos se desvelaban progresivamente:

[...] la narrativa es un arte tan lábil como pueda serlo el sentido de las palabras con que se construye; que no brinda seguridades, ni siquiera en eso que, en otros oficios, se llama capacitación profesional: el carpintero se siente más capaz, mejor dotado después de hacer una mesa; sin embargo, el novelista se encuentra ante cada obra tan desprotegido como el jugador de ruleta que, en cada tirada, vuelve a empezar desde cero ${ }^{46}$.

De Rojas aprende que la palabra puede ser, alternativa o simultáneamente, sinónimo de poder, fuente de sospecha tanto como de conocimiento, traslación de una experiencia $\mathrm{y}$, en ocasiones, posibilidad de resistencia: 
Para Rojas, la lengua es un territorio de saqueo. La palabra no sirve para conocer, sino que da poder, domina y esconde. [...] todo el texto [...] está construido como un ejercicio de íntimo recelo hacia el aparato cultural. [...] Frente al culto a la palabra, tan propia del Renacimiento, ella propone la sospecha: su recorrido a través de los estilos -de arriba abajo; de la cita clásica, o piadosa, a la obscenidad- es un paseo a través de los engaños de la literatura. [...] a uno no acaba de quitársele de la cabeza que el verdadero demonio que interviene en esta obra es la palabra que todo lo trastrueca, lo confunde, emborracha y ciega. Pero la palabra es el instrumento con el que uno construye el mundo en su cabeza ${ }^{47}$.

Construir mundos, o destruirlos, es lo que pretende hacer el autor y para ello se sirve de múltiples personajes no solo incomunicados y en conflicto: mintiéndose a sí mismo respecto a Liliana, Esteban nos muestra que es de poco fiar. En otras novelas también tenemos ejemplos de narradores poco fiables, independientemente de su lucidez respecto a la mentira, su buena o mala fe. El autor pretende «desenmascarar los saqueos de unos y otros» en relación a su propia memoria ${ }^{48}$ :

He sometido las coordenadas de mi educación sentimental al juego de espejos de narradores poco fiables, para alertarme a mí mismo -y al lector- acerca de la necesidad de saber moverse entre la seducción de los lenguajes; he fomentado la desconfianza de eso que parece flotar por encima de todas las cosas y que conocemos como cultura: «La buena letra es el disfraz de las mentiras», dice Ana; y Carlos Císcar, el personaje de Los disparos del cazador, es un narrador estrepitosamente poco fiable [...], pero que, desde su falacia, acaba desnudando los valores de la nueva clase, del mismo modo que lo hará -al final de este viaje literario- Rubén Bertomeu, el protagonista de Crematorio ${ }^{49}$.

Construye Chirbes sus personajes de tal modo que son la esencia de las novelas como en Galdós ${ }^{50}$, teniendo en cuenta ciertos referentes teóricos como el dialogismo y la polifonía de M. Bajtín y el principio de escritura-constelación de W. Benjamin para un convencido de que «la gran novela europea nace del enfrentamiento de lenguajes»" Aplicados al ámbito de la novela tenemos los referentes prácticos del perspectivismo de Cervantes, Galdós y de Max Aub, e incluso más cerca en el tiempo, de Marsé de quien toma la idea de que la memoria es «una forma de intemperie» ${ }^{2}$.

De ahí la centralidad dada a determinado tratamiento del espacio y del tiempo, siendo irónicamente descentrada ${ }^{53}$, así como al lenguaje y al estilo para construir los discursos de los personajes, a esos monólogos interiores de gran efecto erosivo que permiten trasladar la idea de conflictividad entre personajes (perspectivismo siempre irreconciliable), la inestabilidad del espacio literario que es la novela, que dice aprender de Cervantes ${ }^{54}$, el interés de tratar ciertas temáticas prosaicas como en Balzac y Galdós, y la mezcla resultante de crudeza y de lirismo. Recurrir a la noción de ethos puede resultar fecundo para analizar las estrategias discursivas llevadas a cabo por un personaje que, mediante una escenografía de sus circunstancias individuales e históricas, apela a la complicidad del lector y en ocasiones lo incomoda, si es que consigue dejar sus propias falacias al descubierto ${ }^{55}$.

41 Esta fue la ambición novelística resueltamente abarcadora del individuo inmerso en una época desde una visión pragmática de la narrativa, sin por ello desdeñar el estilo, puesto que «escribir una literatura con voluntad de intervención, señaladamente crítica, no debería implicar renuncias estéticas $»^{56}$. Lamentablemente desaparecido Chirbes, nos deja una exploración sutil de la realidad de nuestro tiempo a partir de patrones universales. Podemos suponer que el realismo venidero seguirá 
experimentando adaptaciones para enlazar una literatura comprometida con la ética y la estética.

\section{BIBLIOGRAFÍA}

Nuria AZANCOT (2007), «Rafael Chirbes: 'Crematorio me ha llenado de dudas y me ha tenido en un pozo oscuro durante muchos meses'» [on-line], El Cultural (actualizado el 27/12/2007) [consultado el 3/05/2021] <URL: https://www.anagrama-ed.es/view/10802/Crematorio-ElMundo2007.pdf>.

Manuel AZNAR SOLER, República literaria y revolución, Sevilla, Renacimiento, 2010.

Gaston BACHELARD, La poétique de l'espace, Paris, Presses Universitaires de France, 1957.

Mijail BAJTIN, Teoría y estética de la novela [traducción de Helena S. Kriúkova y Vicente Cazcarra], Madrid, Taurus, 1989.

Roland BARTHES, «L'ancienne rhétorique : aide-mémoire», Communications, n 16 (1970), p. 172-223. Cécile BEAU, «Le motif du spectre dans la littérature de l'exode rural en Espagne (1978-2015)» [online], Marine Auby-Morici, Silvia Cucchi (dir.), Spectralités dans le roman contemporain : Italie, Espagne, Portugal, Paris, Presses Sorbonne Nouvelle, 2017 (actualizado el 6/11/2018) [consultado el 12/04/2021] <URL : http://books.openedition.org/psn/7389>.

Jean-Marc BESSE, Pascal CLERC, Marie-Claire ROBIC, «Qu'est-ce que le 'spatial turn' ?» [online], Revue d'histoire des sciences humaines, $\mathrm{n}^{\circ} 30$ (2017) (actualizado el 3/12/2018) [consultado el 3/05/2021] <URL: http://journals.openedition.org/rhsh/674>.

María del Carmen BOBES NAVES, «Los espacios novelescos en 'La Regenta'», Los Cuadernos del Norte, $\mathrm{V}, \mathrm{n}^{\circ} 23$ (enero-febrero 1984), p. 51-57.

Jessica CÁLIZ MONTES, «En la orilla de Rafael Chirbes: una alegoría de la crisis económica», Raquel Crespo-Vila y Sheila Pastor (eds), Dimensiones. El espacio y su significado en la literatura hispánica, Madrid, Biblioteca Nueva, 2017, p. 385-393.

Jean-François CARCELÉN, «En la orilla de Rafael Chirbes: paisaje después de la canalla», Ínsula, $\mathrm{n}^{\circ} 803$ (noviembre 2013), p. 11-13.

Rafael CHIRBES, El novelista perplejo, Barcelona, Anagrama, 2002.

Rafael CHIRBES, Crematorio, Barcelona, Anagrama, 2007.

Rafael CHIRBES, Por cuenta propia. Leer y escribir, Barcelona, Anagrama, 2010.

Rafael CHIRBES, En la orilla, Barcelona, Anagrama, 2013.

Rafael CHIRBES (2014), RTVE, «Entrevista a Rafael Chirbes» [on-line], Página 2 (actualizado el 23/03/2014) [consultado el 3/05/2021] <URL: http://www.rtve.es/alacarta/videos/pagina-dos/ pagina-2-entrevista-rafael-chirbes/2464596/>.

Rafael CHIRBES, Librairie Mollat, Sur le rivage, (ediciones Rivages, 2015, [traducción de Denise Laroutis]), 2015 (actualizado el 12/01/2015) [consultado el 3/05/2021] <URL: https:// www.youtube.com/watch?v=poC4bJu8d48>. 
Juan-Eduardo CIRLOT, Diccionario de símbolos, Barcelona, Labor, 1981.

Stephen CLINGMAN, The Grammar of Identity: Transnational Fiction and the Nature of the Boundary, New York, Oxford University Press, 2009.

Bernard DEBARBIEUX, «Le lieu, le territoire et trois figures de rhétorique», L'Espace géographique, $n^{\circ} 24 / 2$ (1995), p. 97-112.

Santiago FERNÁNDEZ (2002), «Rafael Chirbes: los libros siempre saben más que su autor» [on-line], Babab, 11 [consultado el 30/04/2021] <URL: https://www.babab.com/no11/rafael_chirbes.htm>.

Michel FoUCAULT, «Des espaces autres» [on-line], Empan, vol. 2, n 54 (2004), p. 12-19 [consultado el 3/05/2021] <URL: https://www.cairn.info/revue-empan-2004-2-page-12.htm>.

Gérard GENETTE, Figures III, Paris, Seuil, 1972.

Elena HEVIA (2013), «Rafael Chirbes: España es un pantano que todo lo va pudriendo» [on-line], El Periódico (actualizado el 20/03/2013) [consultado el 3/05/2021] <URL: https://

www.elperiodico.com/es/ocio-y-cultura/20130320/rafael-chirbes-espana-es-un-pantano-quetodo-lo-va-pudriendo-2345048>.

Christian JACOB, «Spatial turn» [on-line], Christian Jacob (ed.), Qu'est-ce qu'un lieu de savoir?, Marseille, OpenEdition Press, 2014 (actualizado el 23/09/2014) [consultado el 3/05/2021] <URL: http://books.openedition.org/oep/654>.

Mikel LABASTIDA (2015), «De Mimoun a Misent, los rincones literarios del universo del autor» [online], Lasprovincias.es (actualizado el 16/09/2015) [consultado el 3/05/2021] <URL: https:// www.lasprovincias.es/culturas/201508/16/mimoun-misent-rincones-literarios-20150816004504v.html>.

Jimena LARROQUE, De lo político en la novela. Una lectura crítica de En la orilla de Rafael Chirbes, Binges, Orbis Tertius, 2020.

Jimena LARROQUE, «Las coordenadas de la perdición: espacio y tiempo en En la orilla», Javier LluchPrats (ed.), El universo de Rafael Chirbes, Barcelona, Anagrama, 2021, p. 379-396.

Javier LLUCH-PRATS, «Escritores españoles ante la crisis: propuestas de una literatura de intervención social» [on-line], HispanismeS, nº 9 (2017), p. 4-16 (actualizado el 5/06/2017) [consultado el 3/05/2021] <URL : https://hispanistes.fr/images/PDF/HispanismeS/ Hispanismes_9/2_LLUCH-PRATS_Javier_HispanismeS_9.pdf >.

Dominique MAINGUENEAU, «Ethos, scénographie, incorporation», Ruth Amossy (ed.), Images de soi dans le discours. La construction de l'ethos, Lausanne, Delachaux et Niestlé, 1999, p. 75-100.

Dominique MAINGUENEAU, «L'èthos : un articulateur» [on-line], COnTEXTES, 13, 2013 (actualizado el 20/12/2013) [consultado el 3/05/2021] <URL: http://journals.openedition.org/contextes/5772>.

Isabelle MORNAT, «De Marx a Poe: notas para una poética de la crisis. En la orilla, Rafael Chirbes» [on-line], HispanismeS, n 9 (2017), p. 58-75 (actualizado el 7/06/2017) [consultado el 3/05/2021] $<\mathrm{URL}$ : https://hispanistes.fr/images/PDF/HispanismeS/ Hispanismes_9/6_MORNAT_Isabelle_HispanismeS_9.pdf >.

Ignacio MUÑoz, «Introducción», en Rafael Chirbes, Los disparos de cazador, Barcelona, Castalia, 2001, p. 7-45.

Álvaro ROMERO MARCO, «La perplejidad necesaria de Rafael Chirbes (Reflexiones para el debate entre novela y novela)», Augusta López Bernasocchi y José Manuel López de Abiada (eds.), La constancia de un testigo. Ensayos sobre Rafael Chirbes, Madrid, Editorial Verbum, 2011, p. 465-477. 
Annabelle SEOANE (2015), «Ethos» [on-line] Publictionnaire. Dictionnaire encyclopédique et critique des publics (actualizado el 3/06/2021) [consultado el 3/05/2021] <URL: http://publictionnaire.humanum.fr/notice/ethos>.

Daniela Cecilia SERBER, «La literatura como búsqueda. Conversaciones con Rafael Chirbes», Cristina Somolinos Molina (ed.), «Escrituras del cuerpo: Marta Sanz», Olivar, vol. 18, $\mathrm{n}^{\circ} 27$ (junio 2018), s. p.

Marta SIMó, «Ética y estética en la novela realista contemporánea: de Miau (1888) a Animales domésticos (2003)», Pasavento. Revista de Estudios Hispánicos, vol II, oㅡ 1 (invierno 2014), p. 33-56.

Gonzalo SOBEJANO, «La novela ensimismada (1980-1985)», España Contemporánea, I, nº 1 (1988), p. 9-26.

Manuel SOLLO FERNÁNDEZ, «En la orilla, Chirbes y la crisis», Biblioteca pública, RNE, 14 de enero de 2014, s. p.

Robert T. TALLY JR. (ed.), The Routledge Handbook of Literature and Space, London/New York, Routledge, 2017.

Fernando VALLS (2013), «La podredumbre según Chirbes» [on-line], El País (actualizado el 28/02/2013) [consultado el 3/05/2021] <URL: https://elpais.com/cultura/2013/02/28/actualidad/ 1362072006_442132.html>.

\section{NOTAS}

1. Rafael CHIRBES, El novelista perplejo, Barcelona, Anagrama, 2002, p. 83.

2. Jimena LARRoQue, De lo político en la novela. Una lectura crítica de En la orilla de Rafael Chirbes, Binges, Orbis Tertius, 2020.

3. Jimena LARROQUE, «Las coordenadas de la perdición: espacio y tiempo en En la orilla», Javier Lluch-Prats (ed.), El universo de Rafael Chirbes, Barcelona, Anagrama, 2021, p. 379-396. Dicha publicación se integra en una obra que recoge una treintena de ensayos cuyos autores participaron en el I Congreso Internacional «El universo de Rafael Chirbes», celebrado en mayo de 2018, treinta años después de la publicación de Mimoun, su primera novela (Anagrama, 1988).

4. María del Carmen BOBES NAVES, «Los espacios novelescos en 'La Regenta'», Los Cuadernos del Norte, $\mathrm{V}, \mathrm{n}^{\circ} 23$ (enero-febrero 1984), p. 51.

5. Robert T. TALLY JR. (ed.), The Routledge Handbook of Literature and Space, London/New York, Routledge, 2017.

6. Christian JАСОВ, «Spatial turn» [on-line], Christian Jacob (ed.), Qu'est-ce qu'un lieu de savoir?, Marseille, 2014, OpenEdition Press (actualizado el 23/09/2014) [consultado el 3/05/2021] <URL: http://books.openedition.org/oep/654>; Jean-Marc BESSE, Pascal CLERC, Marie-Claire ROBIC (2017), "Qu'est-ce que le 'spatial turn'?» [on-line], Revue d'histoire des sciences humaines, $\mathrm{n}^{\circ} 30$ (actualizado el 3/12/2018) [consultado el 3/05/2021] <URL: http://journals.openedition.org/ rhsh/674>.

7. Bernard DEBARBIEUX, «Le lieu, le territoire et trois figures de rhétorique», L'Espace géographique, $n^{\circ} 24 / 2,1995$, p. 97-112.

8. Esta noción fue expuesta por el filósofo francés en una conferencia de 1967 y publicado como artículo en la obra póstuma Dits et écrits (Gallimard, 1994), disponible en: Michel FOUCAULT, «Des espaces autres» [on-line], Empan, vol. 2, n 54 (2004), p. 12-19 [consultado el 3/05/2021] <URL: https://www.cairn.info/revue-empan-2004-2-page-12.htm>. 
9. Mikel LABASTIDA (2015), «De Mimoun a Misent, los rincones literarios del universo del autor» [online], Lasprovincias.es (actualizado el 16/09/2015) [consultado el 3/05/2021] <URL: https:// www.lasprovincias.es/culturas/201508/16/mimoun-misent-rincones-literarios-20150816004504v.html>.

10. En esta novela también figura Bovra localidad cercana a Misent y trasunto de Tavernes de la Valldigna (Valencia), lugar de nacimiento del autor, y que también es uno de los lugares de la novela corta El año que nevó en Valencia (Anagrama, 2017).

11. Ignacio MUÑOZ, «Introducción», Rafael Chirbes, Los disparos de cazador, Barcelona, Castalia, 2011, p. 27.

12. Según palabras del propio autor, en una entrevista en la que presentaba su novela traducida al francés: Librairie Mollat, Sur le rivage, 2015 (ediciones Rivages, 2015 [traducción de Denise Laroutis]) (actualizado el 12/01/2015) [consultado el 3/05/2021] <URL: https:// www.youtube.com/watch?v=poC4bJu8d48>.

13. Esta «cultura del pelotazo» es denunciada por Esteban al traer a colación «[...] los tiempos felices en que -según el ministro socialdemócrata de economía [Carlos Solchaga]- España era el país de Europa en que se podía ganar más dinero en menos tiempo» (Rafael CHIRBES, ELO, op. cit. p. 268).

14. Rafael CHIRBES (2014), RTVE, «Entrevista a Rafael Chirbes» [on-line], Página 2 (actualizado el 23/03/2014) [consultado el 3/05/2021] <URL : http://www.rtve.es/alacarta/videos/pagina-dos/ pagina-2-entrevista-rafael-chirbes/2464596/ >

15. Es probablemente Olba inspiración de Orba, localidad de la comarca de la Marina Alta con quien guarda una proximidad fonética, si bien otra localidad llamada Olba existe realmente en la comarca Gúdar-Javalambre, provincia de Teruel, lindando con la Comunidad Valenciana.

16. En adelante, para citar páginas de $E L O$, pondremos únicamente el número de página entre paréntesis.

17. Rafael CHIRBES, Crematorio, Barcelona, Anagrama, 2007, p. 415.

18. Dejemos apuntada la definición del «cronotopos artístico» de M. Bajtín, entendido como «una categoría de la forma y el contenido en literatura [en la que] tiene lugar la unión de los elementos espaciales y temporales en un todo inteligible y concreto», Mijail BAJTIN, Teoría y estética de la novela [traducción de Helena S. Kriúkova y Vicente Cazcarra], Madrid, Taurus, 1989, p. 237-238.

19. Manuel SOLlo FERNÁNDEZ, «En la orilla, Chirbes y la crisis», Biblioteca pública, RNE, 14 de enero de 2014, s. p.

20. Jean-François CARCELÉN, «En la orilla de Rafael Chirbes: paisaje después de la canalla», Ínsula, $\mathrm{n}^{\circ} 803$, noviembre de 2013, p. 13.

21. Juan-Eduardo CIRLOT, Diccionario de símbolos, Barcelona, Labor, 1981, p. 354.

22. Elena HEVIA (2013), «Rafael Chirbes: España es un pantano que todo lo va pudriendo» [on-line], El Periódico (actualizado el 20/03/2013) [consultado el 3/05/2021] <URL: https:// www.elperiodico.com/es/ocio-y-cultura/20130320/rafael-chirbes-espana-es-un-pantano-quetodo-lo-va-pudriendo-2345048>.

23. La cursiva es nuestra (véase Fernando valLS (2013), «La podredumbre según Chirbes» [on-line], El País (actualizado el 28/02/2013) [consultado el 3/05/2021] <URL: https://elpais.com/cultura/ 2013/02/28/actualidad/1362072006_442132.html>.

24. Isabelle MORNAT, «De Marx a Poe: notas para una poética de la crisis. En la orilla, Rafael Chirbes» [on-line], Hispanismes, $\mathrm{n}^{\circ} 9$ (2017), p. 75 (actualizado el 7/06/2017) [consultado el 3/05/2021] <URL: https://hispanistes.fr/images/PDF/HispanismeS/ Hispanismes_9/6_MORNAT_Isabelle_HispanismeS_9.pdf >.

25. Jessica CÁlIz MONTES, «En la orilla de Rafael Chirbes: una alegoría de la crisis económica», Raquel Crespo-Vila y Sheila Pastor (éds), Dimensiones. El espacio y su significado en la literatura hispánica, Madrid, Biblioteca Nueva, 2017, p. 386. 
26. Dominique MAINGUENEAU, «Ethos, scénographie, incorporation», Ruth Amossy (ed.), Images de soi dans le discours. La construction de l'ethos, Lausanne, Delachaux et Niestlé. 1999, p. 75-100.

27. Annabelle SEOANE «Ethos» [on-line] Publictionnaire. Dictionnaire encyclopédique et critique des publics (actualizado el 3/06/2021) [consultado el 3/05/2021] <URL: http://publictionnaire.humanum.fr/notice/ethos>.

28. A excepción de dos intervenciones de un narrador heterodiegético, los demás son todos narradores y personajes (homodiegéticos pues) que en algún momento gobiernan su propio parlamento (Gérard GENETTE, Figures III, Paris, Seuil, 1972).

29. Roland BARTHES, «L'ancienne rhétorique: aide-mémoire», Communications, $\mathrm{n}^{\circ} 16,1970$, p. 172-223.

30. Gaston BACHELARD, La poétique de l'espace, Paris, Presses Universitaires de France, 1957, p. 168.

31. Manuel AZNAR SOLER, República literaria y revolución, Sevilla, Renacimiento, 2010, p. 24.

32. Como excepciones de diálogos, podemos señalar dos escenas corales en el bar de olba (p. 54-71 y de p. 248-259), así como algunos intercambios directos, aunque en analepsis y, por lo tanto, filtrado otra vez por Esteban, entre el susodicho y Francisco.

33. Mijail BAJTIN, Teoría y estética de la novela [traducción de Helena S. Kriúkova y Vicente Cazcarra], Madrid, Taurus, 1989, p. 384.

34. Cécile BEAU, «Le motif du spectre dans la littérature de l'exode rural en Espagne (1978-2015 » [on-line], Marine Auby-Morici, Silvia Cucchi (dir.), Spectralités dans le roman contemporain: Italie, Espagne, Portugal, Paris, Presses Sorbonne Nouvelle, 2017 (actualizado el 6/11/2018) [consultado el 12/04/2021] <URL : http://books.openedition.org/psn/7389>.

35. Dominique MAINGUENEAU, «L'èthos: un articulateur» [on-line], COnTEXTES, 13, 2013 (actualizado el 20/12/2013) [consultado el 3/05/2021] <URL: http://journals.openedition.org/ contextes/5772>.

36. Rafael CHIRBES, El novelista perplejo, Anagrama, Barcelona, 2002, p. 84.

37. Ibid., p. 83.

38. Marta sıMó, «Ética y estética en la novela realista contemporánea: de Miau (1888) a Animales domésticos (2003)», Pasavento. Revista de Estudios Hispánicos, Vol II, n 1 (invierno 2014), p. 39.

39. Ibid., p. 36

40. Gonzalo SOBEJANO, «La novela ensimismada (1980-1985)», España Contemporánea, I, nº 1 (1988), p. 9-26.

41. Rafael CHIRBES, El novelista perplejo, op. cit., p. 112.

42. Nuria AZANCOT (2007), «Rafael Chirbes: 'Crematorio me ha llenado de dudas y me ha tenido en un pozo oscuro durante muchos meses'» [on-line], El Cultural (actualizado el 27/12/2007) [consultado 3/05/2021] <URL: https://www.anagrama-ed.es/view/10802/Crematorio-ElMundo2007.pdf>.

43. Jimena LARROQUE, De lo político en la novela, op. cit., p. 111-114 (véase Stephen CLINGMAN, The Grammar of Identity: Transnational Fiction and the Nature of the Boundary, New York, Oxford University Press, 2009).

44. Rafael CHIRBES, Por cuenta propia. Leer y escribir, Barcelona, Anagrama, 2010, p. 57 et 59.

45. Daniela Cecilia SERBER, «La literatura como búsqueda. Conversaciones con Rafael Chirbes», Cristina Somolinos Molina (ed.), «Escrituras del cuerpo: Marta Sanz», Olivar, vol. 18, $\mathrm{n}^{\circ} 27$ (junio 2018), s. p.

46. Rafael CHIRBES, Por cuenta propia...,op. cit., p. 12.

47. Ibid., p. 53-54.

48. Álvaro ROMERO MARCO, «La perplejidad necesaria de Rafael Chirbes (Reflexiones para el debate entre novela y novela)», Augusta López Bernasocchi y José Manuel López de Abiada (eds.), La constancia de un testigo. Ensayos sobre Rafael Chirbes, Madrid, Editorial Verbum, 2011, p. 472.

49. Rafael CHIRBES, Por cuenta propia...,op. cit., p. 33. 
50. «Yo no he hecho una novela de la transición, por ejemplo, he hecho una novela de personajes en la transición. Galdós no hace una novela de la época isabelina: Galdós hace a Torquemada y nos emociona» (entrevista de Santiago FERNÁNDEZ, «Rafael Chirbes: los libros siempre saben más que su autor» [on-line], Babab, no 11 (2002) [consultado el 30/04/2021] <URL: https:// www.babab.com/no11/rafael_chirbes.htm>.

51. Rafael CHIRBES, Por cuenta propia..., op. cit., p. 25-26.

52. Rafael CHIRBES, El novelista perplejo, op. cit., p. 102.

53. «Un punto de vista que Chirbes sitúa en los ángulos y no en el centro. Ya que es mirando y plasmando la realidad desde el descentramiento de la memoria y el compromiso cívico [...] desde donde el novelista puede relacionarse con el mundo y ayudar a mejorarlo» (véase Álvaro ROMERo MARCo, op. cit., p. 473).

54. Rafael CHIRBES, Por cuenta propia..., op. cit., p. 96.

55. En este sentido, Chirbes puede resultar un «escritor incómodo» (véase Ignacio MUÑOz op. cit., p. 9).

56. Javier LLUCH-PRATS, «Escritores españoles ante la crisis: propuestas de una literatura de intervención social» [on-line], HispanismeS, $n^{\circ} 9$ (2017), p. 12-13 (actualizado el 5/06/2017) [consultado el 3/05/2021] <URL: https://hispanistes.fr/images/PDF/HispanismeS/ Hispanismes_9/2_LLUCH-PRATS_Javier_HispanismeS_9.pdf>.

\section{RESÚMENES}

Este es un estudio dedicado específicamente al espacio y a los personajes de la novela En la orilla (Anagrama, 2013) de Rafael Chirbes (1949-2015). En los márgenes de una dimensión espacial asfixiante, fruto de la imaginación diegética del autor, los personajes-narradores sufren un proceso de destrucción de su ethos contenido en discursos que se caracterizan por su condición de incomunicabilidad entre sí: solo el lector recibe la enunciación de la que, por tanto, es el único testigo. Alegoría de la época contemporánea, este texto es una pieza en la obra novelística de un autor que, tras su muerte, sigue contribuyendo a la práctica de la novela realista en el siglo XXI.

Voici une étude consacrée spécialement à l'espace et aux personnages dans le roman En la orilla (Anagrama, 2013) de Rafael Chirbes (1949-2015). Dans les marges d'une dimension spatiale asphyxiante, fruit de l'imagination diégétique de l'auteur, les personnages-narrateurs subissent un processus de destruction de leur ethos contenu dans des discours qui se caractérisent par leur condition d'incommunicabilité entre eux : seul le lecteur reçoit l'énonciation dont il est ainsi le seul témoin. Allégorie de l'époque contemporaine, ce texte constitue une pièce dans l'œuvre romanesque d'un auteur qui, après sa mort, contribue toujours à une pratique du roman réaliste au $\mathrm{XXI}^{\mathrm{e}}$ siècle.

This is a study devoted specifically to space and characters in the novel En la orilla (Anagrama, 2013) by Rafael Chirbes (1949-2015). In the margins of an asphyxiating spatial dimension, fruit of the author's diegetic imagination, the characters-narrators undergo a process of destruction of their ethos contained in discourses that are characterized by their condition of incommunicability among themselves: only the reader receives the enunciation of which he or she is thus the only witness. An allegory of the contemporary era, this text is a piece in the novelistic work of an 
author who, after his death, still contributes to the practice of the realist novel in the 21st century.

ÍNDICE

Palabras claves: Rafael Chirbes, espacio, personajes, ethos, realismo

Keywords: Rafael Chibes, space, characters, ethos, realism

Mots-clés: Rafael Chirbes, espace, personnages, ethos, réalisme

AUTOR

JIMENA LARROQUE

Université d'Orléans 